\section{A psicanálise e a sexologia no Rio de Janeiro de entreguerras: entre a ciência e a auto-ajuda}

Psychoanalysis and
sexology in Rio de Janeiro between the two world wars: between science and self improvement

Jane Araújo Russo

Antropóloga, professora adjunta do Programa de Pós-Graduação em Saúde Coletiva do Instituto de Medicina Social da Universidade do Estado do Rio de Janeiro (IMS/UERJ) Rua do Russel, 32/1002

22210-010 Rio de Janeiro - RJ Brasil jrusso@alternex.com.br

\section{Sérgio Luís Carrara}

Antropólogo, professor adjunto do programa de Pós-Graduação em Saúde Coletiva do Instituto de Medicina Social da Universidade do Estado do Rio de Janeiro (IMS/UERJ) Rua do Russel, 404/601

22210-010 Rio de Janeiro - RJ Brasil scarrara@uerj.com.br
CARRARA, S. L. e RUSSO, J. A.: 'A psicanálise e a sexologia no Rio de Janeiro de entreguerras: entre a ciência e a auto-ajuda'.

História, Ciências, Saúde-Manguinhos,

Rio de Janeiro, vol. 9(2):273-90, maio-ago. 2002.

O início da psicanálise e da sexologia no Brasil se situa na década de 1920 e seu florescimento se dará ao longo das décadas de 1930 e 1940. Esse período assistirá também ao recrudescimento da divulgação de inúmeros trabalhos escritos por outros especialistas sobre sexo e principalmente a tradução e publicação no Brasil de obras de autores europeus e norte-americanos que hoje são considerados os fundadores dessas disciplinas. Gostaríamos de penetrar um pouco nessa nebulosa intelectual que passou a girar em torno do sexo no Brasil daqueles anos. Faremos isso através da análise do mercado editorial do período, explorando a publicação de obras sobre o tema. Procuraremos, a partir da relação diferencial que as novas disciplinas mantiveram com a medicina, compreender as trajetórias distintas que descreveram no campo intelectual brasileiro.

PALAVRAS-CHAVE: sexologia, psicanálise,

sexualidade, história, mercado editorial.

CARRARA, S. L. e RUSSO, J. A.: 'Psychoanalysis and sexology in Rio de Janeiro between the two world wars: between science and self improvement'. História, Ciências, Saúde-Manguinhos, Rio de Janeiro, vol. 9(2):273-90, May-Aug. 2002.

The beginning of psychoanalysis and sexology in Brazil takes place in the 1920's. It develops along the 30's and 40's. During this period, there is also a remarkable increase in the number of papers by other kind of specialists in sex, as well as translations and publications of European and North American authors that are considered today as the founders of such areas of studies. We have tried to go deeper into this intellectual mist, which began to surround the issue of sex in Brazil during that period of time. In order to do so, we have analyzed the publishing industry of the time, focusing the publications on this topic. Starting with the different relations these new subjects established with medicine, we have tried to understand the different trends they produced in Brazilian intellectual domains.

KEYWORDS: sexology, psychoanalysis, sexuality, bistory, publishing industry. 


\section{Introdução}

panorama mais geral que assiste ao surgimento dos primeiros psicanalistas e sexólogos brasileiros parece marcado pela agitação em torno daquilo que, desde o final do século XIX, vinha sendo designado como o "problema" ou a "questão sexual". Em 1928, ao publicar o livro A neurastenia sexual e seu tratamento, o professor de clínica neurológica da Faculdade de Medicina do Rio de Janeiro, Antônio Austregésilo, dizia ter sido motivado a escrever aquele "pequeno manual" devido ao "crescido número de consulentes nervosos, atacados de neurastenia sexual" que vinha tratando em seu consultório. De fato, alguma coisa parecia acontecer com a "libido nacional" naquele período, pois, nos anos seguintes, a capital da república iria assistir à realização de cursos populares sobre sexologia, a comemorações especiais, como o Dia do Sexo; iria ouvir emissões radiofônicas sobre sexo e acompanhar, nos jornais diários, notícias sobre campanhas de educação sexual. Periódicos especializados e novas instituições iriam ser criados especialmente para tratar do tema, que parece ter se tornado tão popular a ponto de fazer com que, no Carnaval de 1935, o tradicional clube carnavalesco Fenianos levasse às ruas um carro alegórico chamado "A educação sexual". Os primeiros sexólogos e psicanalistas iriam então abrir seus consultórios, partilhando a clientela que o professor Austregésilo dizia ser tão numerosa e carente.

No Brasil, na Europa e, embora de modo menos notável, também nos Estados Unidos, os discursos especializados sobre sexo foram articulados sobretudo por médicos. Tais discursos emergiam de uma espécie de nebulosa, cujos vapores emanavam da agitação que a "questão sexual" produzia em diferentes pontos do campo intelectual de então. Tendo no período o mesmo estatuto retórico da "questão social", a "questão sexual" referia-se de modo um tanto inconsistente à percepção de que certas instituições (principalmente o casamento) e valores (principalmente os que equacionavam sexo e imoralidade) eram inadequados ou até mesmo danosos, tendo como conseqüência a proliferação de um conjunto de males sociais que iam da prostituição às doenças venéreas, da pornografia à corrupção de menores, da esterilidade à decadência das nações.

$\mathrm{Na}$ seara da medicina, entre os que se preocupavam com a questão sexual, sobressaíam profissionais de diferentes feitios. Alguns haviam sido treinados em especialidades que detinham grande prestígio - a medicina legal, a psiquiatria, a sifilografia, a eugenia, a higiene ou a ginecologia. Outros se ocupavam de novas especialidades - como era o caso da sexologia e da psicanálise, lutando para adquirir prestígio científico. Enquanto a maioria dos médicos que abordavam o "problema sexual" permanecia nos limites disciplinares de suas especialidades, outros começavam a se 
apresentar publicamente como "sexologistas" e "psicanalistas". E a relação dos médicos assumidamente sexologistas ou psicanalistas com a medicina parece ter sido bastante complicada desde o início.

Em contraste com a psicanálise, que impôs bem mais facilmente sua face respeitável no campo da medicina e da psiquiatria, a sexologia atraía sobre si suspeitas de imoralidade e seus cultores nem sempre escaparam ao estigma de perversos ou pervertidos. ${ }^{1}$ Não parece ser possível, portanto, falar da sexologia no Brasil da primeira metade do século XX sem refletir sobre o estigma que a cercava (e ainda a acompanha) e que em certa medida a manteve como especialidade menor ou subalterna no campo médico e fora dele.

Os que hoje são considerados internacionalmente como os pais da sexologia e também os que, no Brasil, diziam-se sexólogos trabalhavam geralmente com materiais muito díspares, incorporando em suas análises fatos e reflexões oriundos da história, da etnografia, da sociologia, da psicologia, e também da literatura, da filosofia, da moral, do direito. Figuras como Havelock Ellis, na Inglaterra, ou Magnus Hirschfeld e Iwan Bloch, na Alemanha, poderiam muito bem ser considerados como trânsfugas da medicina. ${ }^{2}$ Embora fossem a anatomia e fisiologia dos órgãos sexuais que geralmente imprimiam a aura de cientificidade à nova disciplina, a sexologia que os primeiros sexólogos procuravam criar era algo que ia muito além do estudo do corpo e de seu instinto sexual, dos nervos e sua energia sexual ou das glândulas com seus filtros e hormônios sexuais. Desde o início, a sexologia parece ter sido uma especialidade que, embora tivesse médicos como principais adeptos, apresentava fronteiras bastante porosas, em constante comunicação com as chamadas "humanidades". Além disso, tratava-se de uma disciplina militante, comprometida com um conjunto de reformas sociais que envolviam a defesa de intervenções que iam desde a derrubada das leis que, na Inglaterra ou na Alemanha, ainda criminalizavam a homossexualidade, até a luta pelo divórcio no Brasil ou pelo controle da natalidade, nos Estados Unidos. Podemos dizer que, grosso modo, a disciplina apresentava um projeto de intervenção social herdeiro do iluminismo, no que dizia respeito à luta pela emancipação individual de toda convenção arbitrária, não-natural, mas também do romantismo, quando advogava que tal emancipação deveria passar por um certo reencontro com a natureza, com os instintos, com as energias vitais, dando a elas um fluxo mais livre e espontâneo.

Já a psicanálise mantinha com a medicina uma relação ambígüa de atração e repulsa. A questão da "análise leiga", isto é, da psicanálise praticada por não-médicos, foi motivo de intenso debate entre os primeiros psicanalistas e causa de diversas cisões e dissidências no decorrer da história do movimento. Embora o próprio Freud tenha se pronunciado sobre o assunto, argumentando contra o monopólio médico da psicanálise em trabalho publicado em 1926, pouco tempo 
depois a Associação Psicanalítica Americana decidia banir a "análise leiga", o que causou uma grande crise no seio da International Psychoanalytical Association. ${ }^{3}$ A ascensão do nazismo na Alemanha, com a conseqüente "arianização" do Instituto Psicanalítico de Berlim, o mais importante centro mundial de formação psicanalítica na década de 1920, e a Segunda Guerra Mundial, que provocou a imigração forçada de uma grande quantidade de psicanalistas judeus para a Inglaterra e sobretudo para os Estados Unidos, marcaram um deslocamento do centro de irradiação do saber psicanalítico de Viena para Londres e também a substituição do alemão pelo inglês como língua "oficial" do movimento. A hegemonia da psicanálise anglosaxã tornou-se incontestável, coincidindo com um indubitável reforço do vínculo entre psicanálise e psiquiatria. A penetração da psicanálise no meio psiquiátrico americano, por exemplo, foi notável, a ponto de - nos anos 1950 e 1960 - tornar indispensável ao futuro psiquiatra uma formação em psicanálise. Sua influência nas duas primeiras versões do DSM (Diagnostic and Statistic Manual of Mental Disorders) produzido pela American Psychiatric Association ${ }^{4}$ foi inquestionável.

Como veremos mais adiante, também no Brasil a relação entre as duas disciplinas - sexologia e psicanálise — e a medicina orientou em grande medida suas respectivas trajetórias no meio intelectual e profissional, marcando fortemente sua inserção no mercado editorial.

\section{Os primórdios da sexologia e da psicanálise no Brasil}

No Rio de Janeiro da primeira metade do século XX, são apenas dois os médicos que podem com propriedade ser classificados como sexólogos: o gaúcho Hernani de Irajá e o carioca José de Albuquerque. Irajá cursou a faculdade de medicina em Porto Alegre, transferindose para o Rio de Janeiro, onde ficaria conhecido por extensa produção sexológica e por seu trabalho artístico. Considerado à época um pintor "moderno", Irajá especializou-se em nus femininos, participando de inúmeros salões e exposições. "Talento polimorfo", como diria dele Antônio Austregésilo, mantinha ainda um consultório para consultas sexológicas que era divulgado em suas publicações. ${ }^{6}$

José de Oliveira Pereira de Albuquerque formou-se em medicina no Rio de Janeiro e, ao longo dos anos 1930, notabilizou-se por lutar em prol da educação sexual e da institucionalização da andrologia, nova ciência que, a exemplo do que a ginecologia vinha fazendo com as mulheres, deveria dedicar-se ao estudo dos problemas sexuais do homem. Fundou dois periódicos especializados: o Jornal de Andrologia (1932-38) e o Boletim de Educação Sexual(1933-39). Os livros de Hernani de Irajá seriam divulgados nesses periódicos. Tais publicações foram os órgãos oficiais de duas instituições também criadas por ele: o Círculo 
Brasileiro de Educação Sexual, que, no centro da cidade do Rio de Janeiro, abrigou por vários anos um museu, um posto de aconselhamento e uma pinacoteca, e o Centro Coordenador de Estudos em Andrologia. Albuquerque seria ainda, entre 1936 e 1938, o professor da primeira (e ao que parece única) cátedra de clínica andrológica que existiu em uma universidade brasileira - a Universidade do Distrito Federal.7 E, em 1937, se candidataria a deputado federal com uma plataforma sexológica. Mantinha ainda um consultório especializado no diagnóstico e tratamento da impotência, além de ter lançado no mercado um preventivo para doenças venéreas, o Venereol, cuja fórmula teria inventado.

É importante lembrar que Albuquerque e Irajá nunca pertenceram a quaisquer das prestigiosas academias ou sociedades médicas brasileiras. Pelo contrário, pelo menos no caso do primeiro, parece que sempre estiveram em marcada oposição a elas e ao que significavam. Em seu Jornal de Andrologia (1: 1, 1932), Albuquerque chega mesmo a acusá-las de serem "reminiscência de um regime anti-republicano". ${ }^{8}$ Ao que parece, o reconhecimento profissional só veio de fora e ficou restrito à rede de sexologistas, como atesta o fato de Albuquerque ter sido eleito membro da Sociedade de Sexologia de Paris, em 1937. Em obra publicada no ano de 1943, arrolam-se os títulos de glória do autor, quase todos conquistados ao longo da década de 1930: oficial de reserva do Corpo de Saúde do Exército; membro efetivo da Société de Sexologie de Paris; delegado junto à Union Internationale contre le Peril Vénérien; membro honorário da Sociedade Mexicana de Eugenesia; membro de honra estrangeiro do $1^{\circ}$ Congresso de Eugenia de Lima; membro honorário da $2^{\underline{a}}$ Jornada Peruana Antivenérea; membro honorário do $1^{\circ}$ Congresso de Medicina Interna do México; membro correspondente do Instituto Argentino de la Población; presidente honorário do Comitê de Sexologia do $1^{\circ}$ Congresso Interamericano de Higiene Mental; membro honorário da Sociedade Médica de Valparaíso; membro honorário da Assemblée Générale Contre le Peril Vénérien, reunida em Haia e Amsterdã em 1936 (Albuquerque, 1943).

Esse distanciamento das instituições médicas de maior prestígio não se verifica no caso da psicanálise. Ao contrário, como veremos, os pioneiros da nova especialidade eram, em sua maioria, membros das academias e associações que conferiam aos médicos da época poder e prestígio.

A psicanálise brasileira teve um nascimento "oficial", quando aqui aportaram psicanalistas autorizados pela International Psichoanalytical Association (IPA) para treinar profissionais brasileiros que desejavam obter o título de psicanalista. Esses primeiros grupos, formados em torno dos "emissários" da IPA, fundaram as primeiras sociedades chamadas "oficiais"de psicanálise, inicialmente em São Paulo e depois no Rio (início da década de 1950). A doutrina criada por Freud, entretanto, já 
havia aportado no Brasil muito antes dos emissários oficiais. Já nos anos 1910 e 1920, teorias psicanalíticas se difundiam através de duas vias principais: de um lado, havia uma difusão "leiga", por assim dizer, tanto entre intelectuais e artistas (Mokrejs, 1992; Sagawa, 1985), quanto entre um público leitor anônimo. De outro, a psicanálise era discutida e divulgada por notáveis integrantes do establishment psiquiátrico de então.

Os dois principais personagens da história da psiquiatria brasileira no início do século, Juliano Moreira, no Rio de Janeiro, e Franco da Rocha, em São Paulo, têm seus nomes ligados à difusão da teoria freudiana. Ambos participaram da fundação da primeira Sociedade de Psicanálise Brasileira, em 1927. A seção paulista, primeira a ser fundada, teve como presidente Franco da Rocha. A seção Rio de Janeiro foi fundada no ano seguinte, tendo Juliano Moreira como presidente e Júlio Porto-Carrero como secretário-geral. O reconhecimento provisório pela IPA ocorreria em 1929. Com o objetivo mais genérico de divulgação de trabalhos em torno da psicanálise, congregando intelectuais consagrados que não pertenciam ao meio médico, tais sociedades tiveram curta duração e nunca adquiriram o caráter de sociedades de formação.

De fato, não se pode dizer que a psicanálise penetrou na psiquiatria nacional pela porta dos fundos, muito pelo contrário. Além de Franco da Rocha e Juliano Moreira, outros psiquiatras de renome se interessariam (em diferentes graus) pela psicanálise, utilizando-a em seus trabalhos e expondo-a em suas conferências (Perestrello, 1988; Mokrejs, 1992; Rocha, 1983) Entre estes estavam, além de Porto-Carrero, Arthur Ramos, Henrique Roxo, Maurício de Medeiros, Ulisses Pernambucano, Antônio Austregésilo.? Todos eram (ou se tornaram) catedráticos, seja de psiquiatria (como Henrique Roxo e Maurício de Medeiros) ou de especialidades correlatas (como medicina legal, psicologia social ou neurologia). Foram igualmente membros (alguns deles destacados) da Academia Nacional de Medicina. Evidentemente, o envolvimento com a nova doutrina era desigual. Juliano Moreira e Henrique Roxo, por exemplo, interessaram-se por ela de modo mais periférico, ao contrário de Porto-Carrero ou Arthur Ramos. Antônio Austregésilo com o decorrer do tempo afastou-se da doutrina freudiana, criando uma interpretação bastante pessoal dos distúrbios mentais.

Arthur Ramos iniciou sua carreira como discípulo de Nina Rodrigues, ou seja, vinculado à medicina legal e às discussões em torno da questão racial. Tendo migrado para a psiquiatria, veio para o Rio de Janeiro (a convite de Afrânio Peixoto) onde ocupou a cátedra de psicologia social da Universidade do Distrito Federal e foi nomeado diretor da Seção de Ortofrenia da Secretaria de Educação do Distrito Federal. Também participou da Liga Brasileira de Higiene Mental. ${ }^{10}$ Austregésilo, destacado membro da Academia Nacional de Medicina, foi o primeiro catedrático 
de neurologia da Faculdade Nacional de Medicina, tendo escrito diversos livros de divulgação e aconselhamento, mais ou menos permeados pela teoria psicanalítica.

Entre esses chamados pioneiros da psicanálise, dois merecem tratamento particular: Júlio Pires Porto-Carrero e Gastão Pereira da Silva. Ambos intitulavam-se psicanalistas e, sem dúvida, foram os maiores divulgadores da doutrina freudiana no Rio de Janeiro. Cada um representa uma face da vulgarização da psicanálise na época. Enquanto Porto-Carrero buscava difundi-la entre seus colegas médicos, além de juristas e educadores, e afirmar sua legitimidade científica, Pereira da Silva visava sobretudo a divulgação entre o público leigo.

Porto-Carrero foi catedrático de medicina legal na Faculdade Livre de Direito do Rio de Janeiro. Teve papel bastante ativo nas instituições fundadas no decorrer da Primeira República que procuravam discutir e propor um projeto para a nação, em especial a Associação Brasileira de Educação (ABE) e a Liga Brasileira de Higiene Mental. Aprendeu alemão "aos tropeços" para ler Freud no original, chegando a traduzir para o português O futuro de uma ilusão (publicado em 1934). Publicou nove livros sobre psicanálise ou sobre temas analisados à luz da psicanálise. Fez diversas conferências de divulgação da nova doutrina, não apenas na Liga Brasileira de Higiene Mental e na Associação Brasileira de Educação, ${ }^{11}$ mas também no Círculo do Magistério Superior, no Instituto de Ordem dos Advogados do Brasil e no Círculo Brasileiro de Educação Sexual. ${ }^{12}$ A tais atividades de divulgação somam-se "conferências radiofônicas", de caráter eminentemente educativo. Em sua ambição pedagógica, Porto-Carrero amalgamava psicanálise e eugenia, vendo na teoria psicanalítica um poderoso instrumento promotor de civilização e disciplina.

Em Gastão Pereira da Silva a ambição pedagógica tomou outros rumos. Um dos mais prolixos divulgadores da psicanálise, entre 1930 e 1956 escreveu 16 livros sobre o tema, além de romances, biografias, peças de teatro e novelas de rádio. Sua carreira, ao contrário da de Porto-Carrero, foi desprovida de signos de prestígio acadêmico ou político. Médico do interior, veio para o Rio no final dos anos 1920 e no início dos anos 1930 iniciou sua bem-sucedida carreira de autor psicanalítico, publicando Para compreender Freud. Esse primeiro livro de Pereira da Silva — que em 1942 estará na sua sexta edição - foi publicado a expensas do próprio autor. Os livros seguintes foram publicados por editoras diversas, incluindo a prestigiosa José Olympio, que na década de 1950 iniciaria a publicação de suas obras completas. Dentre os inúmeros títulos de sua autoria encontramos Lenine e a psicanálise, Crime e psicanálise, Neurose do coração, Educação sexual da criança, A psicanálise em doze lições, Conhece-te pelos sonhos, O drama sexual dos nossos filhos, Vícios da imaginação (primeiro publicado pela José Olympio, em 1939, terá seis edições até 1956). O tabu da virgindade, publicado em 1943, 
terá sua quarta edição publicada em 1954. Além dos livros, manteve intensa atividade na imprensa escrita. Em 1934 criou na revista Carioca a coluna 'Psicanálise dos sonhos', ilustrada por uma fotografia de Freud (que deu origem ao livro Conhece-te pelos sonhos). Na revista Vamos Ler manteve uma coluna intitulada 'Página das mães' (da qual nasceu o livro Conheça seu filho). Posteriormente colaborou na revista Seleções Sexuais com a seção 'Confidências'. Manteve durante três anos o programa No mundo dos sonhos, na Rádio Nacional, no qual, segundo suas palavras, "radiofonizava os sonhos (enviados pelos ouvintes), como se fossem pequeninas histórias, em sketchs, interpretadas pelo cast do radioteatro daquela emissora". No mesmo período começou a escrever radionovelas de cunho psicanalítico, e em sua autobiografia lista 44 títulos de sua autoria que foram ao ar. ${ }^{13}$ Criou ainda um curso de psicanálise por correspondência, sobre o qual escreveu: "O poder de penetração desse curso levado, por outro lado, pelo número de uma simples caixa postal, através do rádio, permitiu-me estabelecer contato com muita gente sofredora, esquecida por assim dizer, em certos lugarejos tão distantes, quanto, até mesmo, desconhecidos dos mapas."

Ainda na década de 1930 iniciou sua prática clínica como psicanalista, que manteve até os anos $1980 .{ }^{15}$ Nunca fez parte de qualquer sociedade de formação. Seus livros parecem ter obtido grande sucesso junto ao público leitor, alguns com até 12 edições. Seu objetivo de traduzir os ensinamentos psicanalíticos numa linguagem acessível ao leigo é claramente expresso em seu livro de memórias, onde afirma que até a publicação de seus primeiros livros a psicanálise brasileira era "hermética", erudita, "sem ressonância na alma popular" (Pereira da Silva, 1959).

Quando comparado a Porto-Carrero e outros divulgadores da psicanálise - como Arthur Ramos, Antônio Austregésilo e Maurício de Medeiros -, Gastão Pereira da Silva pode ser considerado como um personagem fronteiriço, a meio caminho entre os prestigiosos acadêmicos e homens públicos dedicados à divulgação da psicanálise e os sexólogos sobre quem pairava a suspeita de interesses escusos. O fato de intitular-se psicanalista e não sexólogo lhe emprestava, em certa medida, algum grau da seriedade e do prestígio de seus colegas acadêmicos. Seus escritos, entretanto, procuravam abordar temas de apelo popular através de uma linguagem simplificada, distante da erudição científica buscada, por exemplo, por PortoCarrero. As citações de autores clássicos da sexologia são abundantes e, como veremos a seguir, a estratégia de publicação das editoras colocava seus livros ao lado de obras sexológicas strito senso.

\section{Sexologia e psicanálise no mercado editorial brasileiro}

Além de afluírem aos consultórios médicos buscando alívio para problemas na esfera sexual, os brasileiros também começavam a consumir 
avidamente o que se escrevia sobre o assunto. ${ }^{15}$ Ao ser publicado no final dos anos 1920, o clássico A questão sexual, do psiquiatra e neurologista suíço Augusto Forel, vendeu os três mil exemplares de sua primeira edição em apenas dois meses. Obra de "êxito editorial sem precedentes", como se leria na orelha de sua décima edição, em 1957, o livro aparecia prefaciado pelo médico-legista Flamíneo Fávero. De fato, embaladas por êxitos editoriais como o de Forel, as livrarias da cidade iriam receber um fluxo crescente de obras sobre sexo e as casas editoras iriam procurar afastar a acusação implícita de que, ao publicálas, estariam apenas cedendo a uma curiosidade "mórbida" do mercado. Assim, por exemplo, quando se publicava em 1946 a terceira edição do livro Psicopatologia da sexualidade, de Hernani de Irajá, o editor fazia questão de esclarecer nas orelhas: "Um modernismo mal entendido criou uma verdadeira avidez em torno de assunto sobre sexualidade ou sexuologia. Aliás, há aí somente um fenômeno de decadência. Mas os homens impressionaram-se de que é preciso estudar questões sexuais. E os livros aparecem e são devorados."

Uma análise, mesmo que superficial, do conjunto dos livros que se publicou sobre sexo no Brasil na primeira metade do século XX revela um mercado editorial bastante diversificado. Várias editoras criaram coleções especiais para acolher tal literatura e, entre elas, merece destaque a que colheu os lucros da citada edição de Forel: a Civilização Brasileira.

A história da Civilização Brasileira é inseparável da de outra grande editora, a Companhia Editora Nacional (CEN). A CEN foi fundada em 1925 por Octalles Marcondes Ferreira e Monteiro Lobato. Por volta de 1929, já produzia um terço dos livros editados na cidade de São Paulo. No início da década de 1930, seu catálogo se caracterizava pelas coleções pedagógicas e didáticas. No seio de sua Biblioteca Pedagógica Brasileira, inaugurada em 1931 e dirigida por Fernando Azevedo, publicou a série Brasiliana, uma coleção que popularizou ensaios sobre a história e a realidade nacionais e que rendeu intenso prestígio para a editora. Em 1932 o proprietário da CEN, Octalles M. Ferreira, ${ }^{16}$ comprou a Livraria Civilização Brasileira, importante editora carioca fundada em 1929. Houve, segundo Sorá (1998, p. 123), uma espécie de divisão de trabalho entre as duas editoras, a Civilização Brasileira ficando com "a edição de literatura orientada para um pólo de leitores mais seletos". Poucos anos depois de sua fundação, a CEN tornou-se a maior empresa editorial do país, sendo responsável, em 1937 pela publicação de um terço de todos os livros editados no país (2.300.000), feito impressionante quando se considera que em 1936 já havia 146 agentes produtores de livros no Brasil. Essa posição é mantida pela editora até os anos 1970.

O livro de Forel foi publicado como parte de uma das coleções da Civilização Brasileira, a Biblioteca de Estudos Psicossexuais, que juntamente com a coleção Biblioteca de Educação Sexual acolhia esse tipo de literatura. Além de Forel, nelas figurariam outros eminentes 
sexólogos estrangeiros. Assim, em 1933, a editora publicava o Matrimônio perfeito - estudo de sua fisiologia e de sua técnica e, em 1937, A aversão ao casamento, com tradução do famoso poeta Manoel Bandeira. Ambos os livros haviam sido escritos pelo ginecologista alemão Theodor Van de Velde (1873-1937). O Matrimônio perfeito foi publicado pela primeira vez em alemão em 1926 e, à mesma época, fazia sucesso estrondoso na Alemanha, Inglaterra e Estados Unidos. Como diz o historiador da sexologia, Vern Bullough (1994, pp. 138-40), embora fosse um "conservador" em muitos assuntos (a homossexualidade, por exemplo), Velde defendia a importância do prazer sexual para a manutenção do casamento e a do orgasmo simultâneo até mesmo para reprodução. Quem prefaciava a edição era o sexólogo brasileiro José de Albuquerque, que não esquecia de também lembrar que:

\begin{abstract}
O inexperiente no comércio de livros pensa que o que leva os editores a aumentar a produção de seus livros, seja a ânsia do lucro, pela fácil aceitação que esses encontram no mercado. Puro engano! Se o livro é de ciência sexual não interessa aos libidinosos, pois estes querem tão-somente livros licenciosos e lúbricos, e não interessa à grande massa do povo, porque esta tem tudo o que é sexual na conta de imoral; por conseguinte os livros de sexologia contam apenas com um círculo reduzido de leitores.
\end{abstract}

Nas palavras de José de Albuquerque transparece novamente o esforço, constante por parte dos sexólogos desse período, em diferenciar seus trabalhos de obras de cunho pornográfico, reafirmando ad nausea o caráter científico do empreendimento ao qual se dedicavam. De todo modo, como vimos, o movimento que acontecia nas editoras atesta que o círculo de leitores não devia ser assim tão reduzido como Albuquerque queria fazer crer.

Entre 1933 e 1936, a Civilização Brasileira e a Companhia Editora Nacional publicariam associadamente pelo menos cinco livros do médico e sexólogo inglês Havelock Ellis (1859-1939), considerado por muitos um dos fundadores da moderna sexologia. A inversão sexual, $A$ educação sexual, O instinto sexual foram os primeiros a serem publicados em 1933, compondo a coleção Estudos de Psicologia Sexual, da Companhia Editora Nacional. A seleção sexual no homem e Opudor, a periodicidade sexual, o auto-erotismo vieram a público respectivamente em 1935 e 1936, através da Civilização Brasileira. ${ }^{17}$ Havelock Ellis já era então um clássico da sexologia, mas seria apresentado ao público brasileiro apenas como membro da Sociedade de Medicina Legal de Nova York. Esse fato exemplifica muito bem o que parece ter sido uma das estratégias das editoras para publicar esse tipo de literatura sem correrem o risco de serem acusadas de licenciosas: apresentar livros de sexologia como sendo trabalhos de disciplinas mais respeitáveis. E, 
entre tais disciplinas, destacava-se sobretudo a medicina legal, que detinha uma espécie de licença para tratar de assuntos moralmente delicados, como a homossexualidade, os crimes sexuais e as então chamadas "degenerações do instinto genésico".

Os dois livros de Ellis traduzidos na primeira metade da década de 1930 no Brasil faziam parte do seu Studies of psychology of sex, uma série de trabalhos cuja publicação fora iniciada em 1896, com o aparecimento na Alemanha de $A$ inversão sexual. Nesses trabalhos, Ellis explorava sobretudo a continuidade existente entre as chamadas anomalias sexuais e o que se considerava ser o comportamento sexual normal. Para Ellis, as chamadas aberrações sexuais ou psicopatias sexuais, como as colecionara o psiquiatra alemão KrafftEbing no final do século XIX, não seriam senão expressões deformadas ou exageradas de elementos presentes no instinto sexual que, nas pessoas "normais", construía os laços afetivos entre os parceiros e assegurava a reprodução da espécie. Segundo Ellis, as "formas elementares" do instinto sexual eram invariáveis e cabia ao sexólogo, através da análise tanto da patologia quanto da fisiologia sexual, estabelecê-las.

Além dos trabalhos de Ellis, a Civilização Brasileira lançaria até os anos 1940 inúmeros outros trabalhos de autores menos conhecidos. Vários trabalhos da paleobotânica inglesa Mary Stopes aparecem antes de 1933. Mary Stopes havia publicado em 1918 Married love, livro que se tornaria uma espécie de libelo em prol do controle da natalidade, da educação sexual e da valorização do sexo no casamento. Em 1936, a editora lançaria a tradução de Monteiro Lobato de $A$ research in marriage, escrito pelo médico e psicólogo Gilbert Van Tassel Hamilton, que o havia publicado nos Estados Unidos, em 1929. O trabalho estatístico de Hamilton sobre o comportamento sexual antecipava alguns dos resultados a que chegaria Alfred Kinsey mais tarde, principalmente o que dizia respeito à freqüência das experiências homossexuais entre homens. Entre os estrangeiros, publicou-se ainda A nossa vida sexual de Fritz Khan, em 1940, e no mesmo ano aparecia A mulher fria, de Wilhem Stekel, um dos primeiros discípulos de Freud.

Entre os brasileiros, a editora publicou em 1935 a quarta edição do já citado Para compreender Freud, de Gastão Pereira da Silva. Da pena do eugenista Octavio Domingues, a Civilização Brasileira publicou Lições de engenia e Hereditariedade e engenia, em 1936. Dos sexólogos, publicou apenas um trabalho de José de Albuquerque, o Catecismo de educação sexual, em 1940. A Companhia Editora Nacional também publicaria à mesma época, em sua coleção Biblioteca Médica, o livro do eugenista Octavio Domingues, Eugenia, seuspropósitos, suas bases, seus meios, em cinco lições (1933), além de inúmeros tratados de urologia e endocrinologia. Como se vê, a Civilização Brasileira e a Companhia Editora Nacional parecem ter tido um certo compromisso com a sexologia e com seu projeto de educação sexual. Montaram coleções 
onde a expressão "sexual" aparecia explicitamente e, entre vários autores, davam lugar a autoproclamados sexologistas, como Havelock Ellis e José de Albuquerque.

Embora a linha editorial da muito mais obscura Editora Calvino se assemelhasse em termos gerais à da Civilização Brasileira/Companhia Editora Nacional, através dos títulos publicados pela Calvino percebese claramente um muito mais ativo anticatolicismo e uma marcada simpatia pelo regime soviético. ${ }^{18} \mathrm{~A}$ Editora Calvino também organizou várias coleções com temas sexuais ao longo dos anos 1930: a Cultura Sexual, os Estudos Sexuais, a Biblioteca de Divulgação Sexual; e, a partir de 1941, lançaria a coleção Freud ao Alcance de Todos. Entre os estrangeiros, deu atenção aos trabalhos do sexólogo, ativista homossexual alemão e grande vítima do regime nazista, Magnus Hirchfeld (1868-1935). Dele publicou em 1940: A alma e o amor, o corpo e o amor, A questão sexual pelo mundo: descrição de costumes sexuais através da história dos povos. Em 1941, sob o mesmo selo, apareceriam: de Havelock Ellis, O sexo através dos séculos; de Freud, Psicanálise da guerra; dos americanos Harry Elmer Barnes e V. F. Calverton, O sexo na educação. Além disso, a Calvino publicou em 1941 uma série de nove livros de autoria de J. Gomes Nerea sobre vários aspectos da obra de Freud. Os tradutores da Calvino não eram famosos como os da Civilização Brasileira/Companhia Editora Nacional e não podemos atestar sobre a qualidade das traduções. Entre os brasileiros, destaca-se a publicação, em 1934, de A mulher no regime proletário, de Gastão Pereira da Silva; e, no mesmo ano, de Educação sexual, de José de Albuquerque.

Unidas no interesse pela sexualidade, sexologia e psicanálise convivem nas mesmas editoras e, por vezes, nas mesmas coleções. Já nessa época, porém, há psicanálise e psicanálise. Entre os brasileiros, apenas Gastão Pereira da Silva — figura, como vimos, "limítrofe" - se aproveitou da convivência com os sexólogos para popularizar a psicanálise. Os trabalhos de autores comprometidos com o establishment médico-psiquiátrico estão ausentes, e serão publicados por outras editoras, como a Guanabara (Koogan-Weissman).

A Guanabara publicou os trabalhos de Porto-Carrero na coleção Biblioteca de Cultura Científica, cujo título mais genérico já indica a preocupação em se afastar de um certo "sensacionalismo" sexualista. Nesta mesma coleção, são divulgados alguns trabalhos de Freud: Totem e tabu e O futuro de uma ilusão, traduzidos diretamente do alemão por Júlio Porto-Carrero, e Introdução à psicanálise, traduzido por Elias Davidovich com autorização do autor. De Porto-Carrero, publicou A psicologia profunda ou psicanálise, em 1932; a Psicanálise de uma civilização e Sexo e cultura (ensaios de psicanalise), ambos em 1933. De Arthur Ramos, as obras Psychiatria e psychanalise e Freud, Adler, Jung... (ensaios de psychanalise ortodoxa e herética) foram publicadas respectivamente em 1933 e 1943; e de Maurício 
de Medeiros, Psychoterapia conceito atual: teoria e prática apareceu também em 1933. Na coleção Biblioteca Brasileira de Medicina Legal, apareciam outros trabalhos de eminentes professores, como Sexologia forense, do professor de higiene da Faculdade de Medicina do Rio de Janeiro, Afrânio Peixoto (1934, $2^{\underline{a}}$ ed.); e $A$ inversão dos sexos, do professor de medicina legal da Bahia, Estácio de Lima (1935). Além de inúmeros tratados de ginecologia e urologia, a editora ainda divulgaria nos anos 1930 trabalhos de Antônio Austregésilo, como Novas aquisições em patologia e terapêutica nervosas, Lições de vida, e Conduta sexual, todos em 1934, e Fames - Libido - Ego, em 1938.

Como se pode perceber, a Guanabara publicava a elite do meio médico brasileiro e, nela, não parecia haver lugar para nomes de sexólogos militantes como José de Albuquerque e Hernani de Irajá, ou mesmo para psicanalistas "selvagens" como Gastão Pereira da Silva. De fato, embora editasse autores que discutiam a "questão sexual", nunca publicou qualquer trabalho estritamente sexológico. Talvez a linha editorial da Guanabara apenas expressasse o desprezo que a elite médica brasileira parecia sentir pela sexologia e seus cultores. E esse parece ser também o caso da Francisco Alves. Essa editora tinha o médico-eugenista Renato Kehl quase como autor cativo desde 1923. Entre os vários títulos desse autor publicados pela Francisco Alves, destaca-se Sexo e civilização: novas diretrizes, de 1933. A elite médica brasileira também aparecia em sua linha editorial. Em 1928, publicava de Antônio Austregésilo o já citado A neurastenia sexual e seu tratamento; em 1929, Conselhos práticos aos nervosos; e em 1932, A educação da alma.Em 1930, lançava, de Afrânio Peixoto, Higiene geral, e, em 1938, publicaria o famoso Homossexualismo e endocrinologia, do professor de medicina legal, Leonídio Ribeiro.

Do mesmo modo que a CEN pode ser considerada a maior editora nacional da época em termos quantitativos, a José Olympio foi, inegavelmente, a de maior prestígio. Segundo Sorá, a livraria da rua do Ouvidor era vista como "uma ante-sala do Panteão". Tendo construído um catálogo composto pelos maiores nomes do que havia de mais moderno na literatura nacional da época, e mantendo com esses autores uma relação pessoal de grande envolvimento, José Olympio tornou-se uma grife que indicava por si só a qualidade da obra publicada. Sua proximidade com a literatura de divulgação sexológico-psicanalítica data de sua fundação. O primeiro livro publicado pela JO em 1932 foi Conheça-te pela psicanálise, de J. Ralph. O segundo título contratado, embora não tenha sido publicado, foi $A$ moral sexual e felicidade na vida, de J. P. Muller (Sorá, 1998, p. 59). Essas primeiras escolhas de um editor iniciante parecem indicar que essa espécie de "auto-ajuda" psicológica era, naquele momento, um investimento seguro.

A história posterior da editora demonstra um distanciamento da sexologia stricto sensu, e uma preferência, no que tange ao "problema 
sexual", pelos autores católicos. De fato, títulos sobre temas sexológicos só apareceram mais tarde, a partir dos anos 1940, no interior de uma coleção intitulada A Ciência Hoje. Entre tais trabalhos destacamse: Você e a hereditariedade e Você e a sexualidade, mulheres e homens, de Amran Scheinfeld, publicados, respectivamente, em 1943 e 1948; Sexo, vitaminas e nutrição (o corpo bumano), de Loyoan Clendening, em 1944 (3ㄹ ed.); A psicanálise ao alcance de todos (o edifício que Freud construiu) exposição e crítica de suas teorias e aplicações, de Josef Jastrow, em 1948; O sexo na vida diária, de Edward F. Griffith, com prefácio de um reverendo, em 1949. Fora da coleção A Ciência Hoje, a José Olympio publicaria o já citado Conheça-te pela psicanálise, de J. Ralph, em 1932, e, em 1936, um livro de Stekel intitulado Educação dos paes, traduzido pelo professor Leme Lopes. Além disso, divulgava inúmeros brasileiros, sobretudo católicos militantes, como Alceu Amoroso Lima, cujo livro Idade, sexo e tempo (três aspectos da psicologia humana) seria publicado em 1938, e o padre Alvaro Negromonte, cujos livros A educação sexual - para pais e educadores e Noivos e esposos, problemas do casamento seriam publicados, respectivamente, em 1939 e 1948.

Como se pode perceber, a sexologia estrangeira ou brasileira permanecia à margem da linha editorial da José Olympio nesse período. O conflito entre os sexólogos brasileiros, principalmente José de Albuquerque, e a Igreja Católica foi intenso durante as décadas de 1920 e 1930 e não devemos estranhar sua ausência, ou a de Hernani de Irajá, entre os autores publicados pela José Olympio. Tal conflito, entretanto, parece não ter atingido tão centralmente a psicanálise. Além das obras já citadas de Ralph, Jastrow e Stekel, três livros de Gastão Pereira da Silva foram publicados pela José Olympio em sua coleção Obras Educativas: Vícios da imaginação, meios de corrigi-los, de 1939 (que chegou à sexta edição em 1956), Como se interpretam os sonhos, de 1943; e Como sepratica a psicanálise, de 1948. Em sua autobiografia, escrita em 1959, Gastão afirma que a editora iria iniciar a publicação de suas obras completas. O fato de uma editora como a José Olympio publicar não apenas um, mas vários de seus livros, significa pelo menos duas coisas. Em primeiro lugar, que Pereira da Silva, embora não fosse, como outros divulgadores da psicanálise, eminente catedrático ou acadêmico, e apesar das inúmeras menções à sexologia encontradas em seus livros, gozava de um prestígio que o diferenciava dos sexólogos, provavelmente associado ao prestígio da própria psicanálise quando comparada com a sexologia. Em segundo lugar, que os temas vinculados à sexualidade, à vida íntima e sobretudo o "aconselhamento" sexual dirigido às camadas letradas da população eram um filão importante para o meio editorial desta primeira metade do século XX. 
Chegamos finalmente à única editora que parece ter se proposto a ser o canal através do qual os sexólogos brasileiros iriam ganhar as prateleiras das livrarias: a Freitas Bastos, que também criaria uma coleção chamada Cultura Sexual. De fato, José de Freitas Bastos parece ter acompanhado de perto o ativismo pró-educação sexual de José de Albuquerque, tendo participado do conselho do Círculo Brasileiro de Educação, entidade que, como vimos, foi fundada pelo sexólogo em 1933 para promoção da educação sexual. Quando fundou o Círculo, Albuquerque já tinha lançado pela Freitas Bastos o que parece ter sido seu segundo livro: Higiene sexual (1929). De Albuquerque, a Freitas Bastos ainda publicaria O perigo venéreo na paz na guerra e no apósguerra, em 1941. De Hernani de Irajá, a editora publicaria Sexualidade e amor, em 1930. Em 1931, editaria Psychoses do amor, estudos sobre as alterações do instinto sexual e Morphologia da mulher — a plástica feminina no Brasil; em 1933, Psicopatologia da sexualidade, Tratamento dos males sexuais e Sexualidade perfeita. Entre trabalhos relevantes relativos à sexualidade, até onde sabemos, a Freitas Bastos iria apenas publicar postumamente dois trabalhos do jurista Francisco José Viveiros de Castro (1862-1906): Os delitos contra a honra da mulher, em 1932, e Atentados ao pudor (estudos sobre as aberrações do instinto sexual), em 1934 ( $3^{\underline{a}}$ ed.). Entre os estrangeiros, destacamos somente o trabalho de Jean Marestan, A educação sexual, publicado pela Freitas Bastos em 1930.

Quanto às editoras que de finais dos anos 1920 e início dos anos 1940 mais estiveram envolvidas na divulgação da literatura sexológica ou sobre temas congêneres, essas parecem ter sido as mais importantes. Não queremos dizer com isso que eram os únicos canais para o escoamento desse tipo de literatura. O sexólogo brasileiro Hernani de Irajá teve pelo menos cinco outros livros publicados pela Irmãos Pongetti, e José de Albuquerque publicaria inúmeros livros pelo seu Círculo Brasileiro de Educação Sexual. A editora Flores e Mano mantinha, nos anos 1930, uma coleção intitulada Biblioteca de Cultura Médico-Psicológica, dirigida pelo psiquiatra Neves-Manta, que publicou Criminologia epsicanálise Ensaios de psicanálise, de PortoCarrero, O meu e o teu: forças psicológicas — o mal das leis biológicas, erros da nutrição e da reprodução, de Antônio Austregésilo, A psychanalise e suas aplicações clínicas, de Carneiro Ayrosa, e Psychanalise da alma coletiva, do próprio Neves-Manta. Enfim, Gastão Pereira da Silva publicaria inúmeros livros em outras editoras e gráficas, tais como Atlantida, Moderna, Mariza, Andersen, Mundo Latino, Espasa e A Noite.

\section{Conclusão}

Do ponto de vista de uma história da sexologia e da psicanálise no Brasil, podemos identificar o período que vai de finais do século XIX até o final dos anos 1920 como momento de crescente divulgação 
de um discurso sobre sexo no Brasil. Mas só na década de 1930 surgirão, às margens das agências mais prestigiosas do campo médico brasileiro, os primeiros profissionais que se autodesignavam como sexólogos e psicanalistas e que trabalhariam em prol da constituição de disciplinas específicas. A posição marginal dos sexólogos é bastante visível quando se olha o mercado editorial brasileiro, onde dificilmente eles partilhavam as mesmas editoras que publicavam os livros dos médicos brasileiros com maior prestígio ou traduziam sexólogos estrangeiros, que, como foi o caso de Ellis, eram às vezes situados em disciplinas mais 'aceitáveis', como a medicina legal.

A psicanálise, por seu turno, tanto se movia para um quanto para o outro extremo do continuum que ia dos autores assumidamente sexológicos aos eminentes catedráticos de medicina legal, neurologia e psiquiatria. Ou seja, sua divulgação junto ao público leigo cobria um espectro mais amplo do que a sexologia stricto sensu, o que pode ser interpretado como um possível prenúncio de seu futuro bem mais brilhante e promissor. De fato, a extrema popularização da psicanálise, que se verificou nas décadas subseqüentes em todos os países do chamado mundo ocidental, conviveu com um não menos intenso prestígio acadêmico - seja como ramo auxiliar da psiquiatria, seja como uma sofisticada teoria sobre o ser humano.

Outras linhas de tensão emergem igualmente da análise do mercado editorial que recebia obras sexológicas. A religião parece ser uma das mais poderosas. Enquanto editoras de prestígio como a José Olympio parecem ter ficado com os autores católicos, editoras com claras tendências marxistas (e, portanto, anticatólicas), como a Calvino, ou dirigidas por judeus, como a Guanabara, parecem ter reservado um espaço maior para a literatura considerada perigosa do ponto de vista dos católicos. Além da religião, a sexologia parece ter padecido os efeitos de tensões oriundas de posições políticas mais abrangentes, tendo dificuldade em se apresentar como uma ciência neutra.

Enfim, relegada a segundo plano por historiadores e sociólogos contemporâneos, o impacto desta literatura sobre comportamentos, crenças e valores das camadas médias letradas brasileiras ainda está por ser analisado. O número de coleções, edições e autores que tratavam de forma direta ou indireta da sexualidade, como vimos, não deixa dúvidas quanto ao apelo popular do tema. O consumo de tal literatura parece indicar claramente um desejo de modernização, de distanciamento de comportamentos e valores então vistos como antiquados ou "atrasados". Desejo este que a sexologia e a psicanálise, sob a forma de uma literatura de auto-ajuda avant la lettre, cuidaram de, ao mesmo tempo, aplacar e aguçar. 


\section{NOTAS}

${ }^{1}$ Até hoje, as pessoas que conheceram os sexólogos brasileiros referem-se a eles ou como exóticos inofensivos, ou como perversos. Nesse sentido, destacou-se sobretudo a figura de Hernani de Irajá, sobre quem pairam acusações de "ambivalência sexual", incesto, taras sexuais, realização de "bacanais". Um dos informantes chegou mesmo a dizer que Irajá teria sido preso na década de 1940 pelo delegado Frota Aguiar (Delegacia de Costumes) por conta das "orgias" que costumava promover em seu consultório. Não pudemos ainda confirmar a informação.

2 Tanto Ellis quanto Hirschfeld desenvolveriam carreiras que abarcavam atividades literárias não relacionadas à medicina ou sexologia.

${ }^{3}$ Há autores que interpretam a grande cisão representada pelo movimento lacaniano na psicanálise francesa como tendo origem nesse conflito surdo entre os partidários do monopólio médico e os que preconizavam a autonomia do campo psicanalítico.

${ }^{4}$ Sendo a primeira publicada em 1952 e a segunda, em 1968

${ }^{5}$ Embora atualmente esquecido, Irajá angariou certo prestígio no meio artístico dos anos 1930 e 1940, tendo alguns de seus quadros incorporados ao acervo do Museu Nacional de Belas Artes. Sua produção iconográfica merece análise à parte uma vez que Irajá usou seu talento para ilustrar seus livros de sexologia, produzindo uma série interessantíssima de gravuras sobre as teorias freudianas. Seus livros vinham ainda entremeados de fotos de mulheres nuas, exemplificando os diferentes biotipos femininos ou os estigmas que marcavam os corpos das perversas e degeneradas.

6 Assim, por exemplo, ao final de seu livro Impotência sexual (Irajá, 1957), aparece a seguinte nota: "O leitor, ou leitora, pode dirigir-se pessoalmente ou por meio de cartas ao dr. Hernani de Irajá, à rua Álvaro Alvim, 24, apartamento 502, em caso de algum esclarecimento que se faça preciso ou desde que se imponha a necessidade de consulta, o que será absolutamente grátis."

${ }^{7}$ Albuquerque dizia-se o fundador da andrologia e procurou defender sua instucionalização na América do Sul e na Europa. Porém, ao que parece, outras tentativas nesse sentido já haviam ocorrido anteriormente no mundo angloamericano. Segundo Ornella Moscucci (1996), em 1887, o ginecologista James Jamieson, de Melbourne, já advogava a necessidade de uma andrologia, como ciência das particularidades mentais e física dos homens. Agradecemos a Fabíola Rhoden a referência ao trabalho de Moscucci.

${ }^{8}$ Para estabelecer a posição marginal que Albuquerque ocupava em relação à elite médica do período temos também outros índices. Em 1935, quando a Universidade do Distrito Federal criou a cátedra de andrologia, Albuquerque disse em tom vitorioso que, ao propor o termo pela primeira vez em 1928, foi muito criticado pela classe médica. Desde então, seu trabalho teria sido uma "luta contra o interesse, luta contra o preconceito, luta contra a rotina e mais que tudo, luta contra o despeito" (Jornal de Andrologia, 4:1, 1935). Seu ressentimento fica também patente quando, em 1935, ao lançar uma pesquisa para saber a opinião dos médicos sobre a andrologia, ressaltava que queria averiguar a opinião do "médico comum" e não a dos "figurões", dos "medalhões", que, segundo ele, estariam "divorciados quase sempre do pensamento de sua classe". Para maiores informações a respeito das posições de Albuquerque, ver Carrara (1996).

${ }^{9}$ Havia também psiquiatras não tão conhecidos (como Carneiro Ayrosa, Neves-Manta ou Murillo de Campos) e nãopsiquiatras, como o jornalista Medeiros e Albuquerque (irmão de Maurício de Medeiros) e o educador Deodato de Moraes.

${ }^{10}$ Fundada em 1923 pelo médico psiquiatra Gustavo Riedel, com o objetivo de divulgar e implantar programas de eugenia e higiene mental no país.

${ }^{11}$ A ABE foi fundada no Rio de Janeiro em 1924 com o objetivo de congregar educadores em torno de um amplo projeto educacional para a nação, englobando a higiene, a moral e a organização do trabalho.

${ }^{12}$ A participação de Porto-Carrero como conferencista numa instituição criada por José de Albuquerque traz à baila a questão dos entrecruzamentos entre sexologia e psicanálise. Porto-Carrero era bastante citado pelos sexologistas brasileiros, embora o contrário não se verificasse.

13 Nos arquivos da Rádio Nacional encontramos radionovelas escritas por Gastão até o final dos anos 1960.

${ }^{14}$ Pereira da Silva faleceu em 1987, aos 91 anos

15 É importante assinalar que o mercado editorial brasileiro como um todo conhece um boom na década de 1930. Entre 1935 e 1936, por exemplo, o número de exemplares publicados sobe em 40\% (Sorá, 1998).

16 Apesar de permanecer vinculado, seja como autor, seja como tradutor ou consultor, à CEN, Lobato vendeu suas ações ao irmão de Ferreira no final dos anos 1920 (Sorá, 1998, pp. 117-8). 
17 Como revela na contracapa de O instinto sexual, a Companhia Editora Nacional planejava ainda publicar de Ellis, O simbolismo erótico, O estado psíquico durante a gravidez - a mãe e a criança, A avaliação do amor, a castidade, a abstinência sexual, A prostituição: suas causas e seus remédios. Não sabemos entretanto se tais livros foram efetivamente publicados. Dos que o foram, à exceção de A seleção sexual no bomem, traduzido pelo médico-legista Leodínio Ribeiro, todos os outros teriam sido traduzidos pelo "dr." Álvaro Eston, a partir da tradução francesa de Arnold van Gennep.

18 Segundo Hallewell (1985, p. 420), a Editora Calvino era estreitamente ligada à seção carioca do Partido Comunista.

\section{REFERÊNCIAS BIBLIOGRÁFICAS}

Albuquerque, José de 1943

Austregésilo, Antônio 1928

Bullough, Vern L. 1994

Carrara, S. 1996

Hallewell, Laurence 1985

Irajá, Hernani de 1957

Mokrejs, Elisabete 1992

Moscucci, Ornella 1996

Pereira da Silva, Gastão 1959

Perestrello, Marialzira 1988

Rocha, Gilberto S. 1983

Sagawa, Roberto 1985

Sorá, Gustavo 1998
Educação sexual.

Rio de Janeiro, Editora Calvino Filho.

A neurastenia sexual e seu tratamento.

Rio de Janeiro, Francisco Alves.

Science in the bedroom: a history of sex research. Nova York, Basic Books.

Tributo a Vênus: a luta contra a sifilis no Brasil, da passagem do século aos anos 40. Rio de Janeiro, Editora Fiocruz.

O livro no Brasil.

São Paulo, Edusp.

Impotência sexual (com um estudo sobre espermatocistites pelo prof. Spinosa Rothier). Rio de Janeiro, Irmãos Pongetti.

A psicanálise no Brasil: as origens do pensamento psicanalítico. Petrópolis, Vozes.

The science of woman: gynecology and gender in England (1800-1929).

Cambridge, Cambridge University Press.

25 anos de psicanálise.

Rio de Janeiro, Livraria Império Editora.

'Primeiros encontros com a psicanálise: os precursores no Brasil (1899-1937).

Em S. A. Figueira (org.), Efeito psi: a influência da psicanálise.

Rio de Janeiro, Campus.

Psicanálise e psiquiatria: uma introdução epistemológica ao surgimento da psicanálise no Brasil. Dissertação de mestrado, Rio de Janeiro, PUC-RJ.

'A psicanálise pioneira e os pioneiros da psicanálise'.

Em S. A. Figueira (org.), Cultura da psicanálise.

São Paulo, Brasiliense.

Brasilianas: a Casa José Olympio e a instituição do livro nacional.

Tese de doutoramento, Rio de Janeiro, Programa de Pós-Graduação em Antropologia Social, Museu Nacional/UFRJ. 